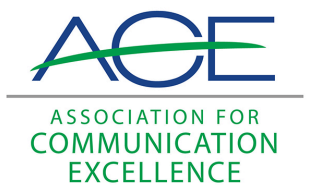

Journal of Applied Communications

\title{
Prior Experience, Perceived Usefulness and the Web: Factors Influencing Agricultural Audiences' Adoption of Internet Communication Tools
}

Tracy Irani

University of Florida

Follow this and additional works at: https://newprairiepress.org/jac

(c) (i) (9)

This work is licensed under a Creative Commons Attribution-Noncommercial-Share Alike 4.0 License.

\section{Recommended Citation}

Irani, Tracy (2000) "Prior Experience, Perceived Usefulness and the Web: Factors Influencing Agricultural Audiences' Adoption of Internet Communication Tools," Journal of Applied Communications: Vol. 84: Iss. 2. https://doi.org/10.4148/1051-0834.2151

This Research is brought to you for free and open access by New Prairie Press. It has been accepted for inclusion in Journal of Applied Communications by an authorized administrator of New Prairie Press. For more information, please contact cads@k-state.edu. 


\title{
Prior Experience, Perceived Usefulness and the Web: Factors Influencing Agricultural Audiences' Adoption of Internet Communication Tools
}

\begin{abstract}
This study, using the Technology Acceptance Model as a theoretical framework, investigated the effect of prior experience on subjects' perceptions of perceived usefulness and intent to use Internet communications tools. Results indicated that respondents who had relevant prior experience had the most favorable perceptions of the perceived usefulness of these technologies. Further, those subjects who had high levels of experience and perceived usefulness were most likely to use Internet communications technologies, while those subjects who scored low in both of these areas were least likely. Linear regression analysis indicated that, for all subjects, experience and perceived usefulness were the strongest predictors of behavioral intent to use Internet communications tools.
\end{abstract}




\section{Prior Experience, Perceived Usefulness and the Web: Factors Influencing Agricultural Audiences' Adoption of Internet Communication Tools}

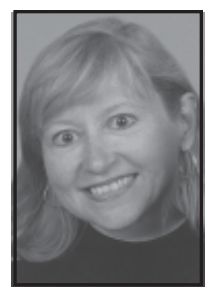

Tracy Irani

\section{Abstract}

This study, using the Technology Acceptance Model as a theoretical framework, investigated the effect of prior experience on subjects' perceptions of perceived usefulness and intent to use Internet communications tools. Results indicated that respondents who had relevant prior experience had the most favorable perceptions of the perceived usefulness of these technologies. Further, those subjects who had high levels of experience and perceived usefulness were most likely to use Internet communications technologies, while those subjects who scored low in both of these areas were least likely. Linear regression analysis indicated that, for all subjects, experience and perceived usefulness were the strongest predictors of behavioral intent to use Internet communications tools.

The Internet is said to be one of the fastest diffusing technological innovations of all time (Nielson, 1995), with an estimated 71 million users worldwide (Matrix Information and Directory Services, 1997). Although still seen as primarily an information carrier, the Internet is also an educational communications tool that represents a potential opportunity for

Tracy Irani is an assistant professor in the Department of Agricultural Education and Communication at the University of Florida. She is an ACE member. This study was unfunded. The research was presented at the Southern Association of Agricultural Scientists 2000 Meeting, Lexington, Kentucky. 
agriculture, where developing more effective communications and a stronger frame of reference, whether it be with students, traditional stakeholders or the general public, has always been a key objective.

One of the oft-cited advantages of Internet use is the degree of interaction and asynchronous communication exchange potentially achievable between sender and receiver. Internet communication tools, which can be defined for the purposes of this study as those applications which facilitate interactive one-to-one communication exchange, include E-mail, chat, World Wide Web-based bulletin boards and on-line discussion forums. In the educational setting, adoption of interactive tools such as these has been shown to augment or extend instruction and information delivery. For example, some studies have found slightly higher student achievement levels when mode of instruction includes interactive computer applications that facilitate communication and collaboration (Martin \& Rainey, 1993; Means, 1993). Yet, within the traditional stakeholder audiences of agricultural students and Cooperative Extension clientele, experience and perception of these technologies for educational communication purposes is still relatively limited. For example, in a three-year longitudinal study, Suvedi, Campo and Lapinski (1999) found that, although the percentage of respondents who used the Web to gain extension-related information increased from $1.4 \%$ to $10 \%$, the vast majority of respondents did not use it. Trede and Whitaker (1998) found that beginning farmers rated "cutting edge," Internet-delivered instructional technologies much lower than traditional instructional techniques, perhaps owing to lack of familiarity and prior experience with these technologies.

Greater usage of Internet communications tools may be a way to meet more effectively the communication needs of students enrolled in on- and off-site agricultural programs (Donaldson \& Thompson, 1999; Miller \& Pilcher, 1999), as well as to help agriculturists communicate with external audiences. Understanding the factors which influence attitude and user perceptions toward technology is therefore a critical need.

The information technology literature includes a number of studies (Davis, 1989; Davis, Bagozzi, \& Warshaw, 1989; Hendrickson \& Collins, 1996; Chau, 1996) utilizing a theoretical framework called the Technology Acceptance Model, or 
TAM, to examine the relationship between user perceptions and adoption of new technologies. Drawing on Fishbein and Ajzen's Theory of Reasoned Action (1975), Davis (1989) developed the TAM to predict usage behavior based on the assumption that individual perceptions as to the ease of use as well as the usefulness of a technology can be used to predict its use. Subsequent research suggests, however, that these relationships are influenced by other external factors, the identification of which might prove useful in helping to predict the likely users of a technology, as well as their attitudes and subsequent usage behavior.

The objective of this study was to examine the assumption that a contextually relevant external factor, the individual's level of prior experience, might exert a specific influence on perceived usefulness, defined in the TAM model as the degree to which a user believes that using a technology will be beneficial in some way. Using the TAM as a theoretical framework, this study was, therefore, designed to examine the effect of prior experience on intent to use Internet-based Internet communication tools to complete a communication task, with a view toward ascertaining how these factors influence adoption of Internet communications technologies. If it can be shown that prior experience is the most significant predictor of intent to use Internet communication tools, agricultural educators and communicators may be able to use this information in the development and positioning of Web-based communication and information delivery initiatives to agricultural audiences.

\section{Conceptual and Theoretical Framework}

\section{The Technology Acceptance Model}

The Technology Acceptance Model, or TAM, stems from the Theory of Reasoned Action, or TORA (Fishbein \& Ajzen, 1975), well known as a seminal work in attempting to understand and predict behavior and behavioral intentions. The TAM attempts to explain user acceptance and adoption of a technology based on two specific behavioral beliefs, perceived ease of use (EOU) and perceived usefulness (U), the influence of which determine an individual's behavioral intention (BI) to use a technology (Figure 1 ). Perceived ease of use is the extent to which it is believed that a technology will be easy to use, while perceived usefulness is the extent to which it is 
believed that using a technology will be beneficial in some way (Venkatesh, 1999).

Figure 1 The Technology Acceptance Model (Hubona \& Geitz, 1999).

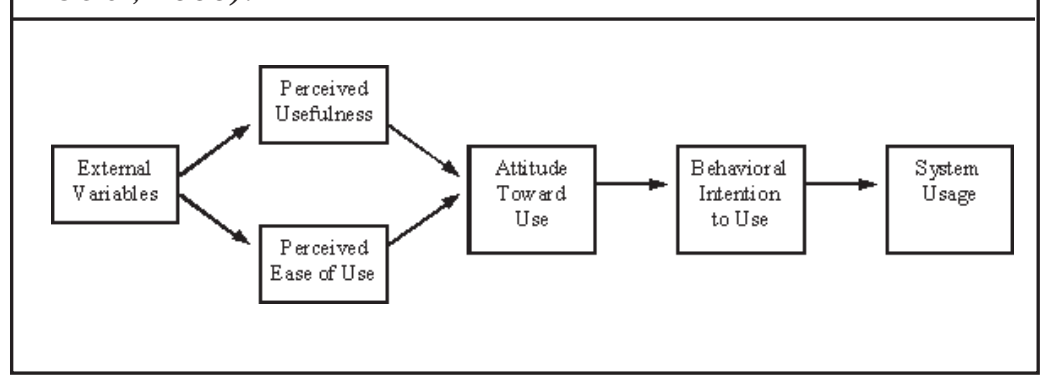

In both the TORA and the TAM, attitudes are a function of beliefs about and assessments of perceived benefits/risks of acting in a certain way, such as beliefs about the advantages or disadvantages of using a new technological innovation. However, two different formulations of TAM exist in the literature. Although many studies in the information technology literature omit attitude, the original model shows the perceived usefulness and perceived ease of use variables influencing attitude toward use, which subsequently impacts usage behavior (Hubona \& Geitz, 1999).

Although Davis et al. (1989) suggested that external variables such as documentation and user support might influence perceived usefulness and ease of use, empirical research on the effect of external variables has been limited. Of the limited research that has been done, Agrawal and Prasad (1997) conducted a study which showed that innovation characteristics (i.e., an individual's perception of the characteristics of an innovation) can predict acceptance behavior. In a subsequent study, the researchers identified a set of individual difference variables, including prior similar experience, that exerted significant influence on TAM's belief constructs (Agrawal \& Prasad, 1999). Doll, Hendrickson and Deng (1998) used multi-group invariance analysis to assess a series of incremental cross-validation studies, the results of which, while providing support for the validity and reliability of the model, also revealed variation from other sub-groups for individuals with no prior computing experience. 


\section{Prior Experience}

Some researchers have argued that behavior is largely a function of an individual's perceptions of an event and its potential outcomes (Fazio, 1995). In this context, one of the critical aspects related to user perceptions of new communications technologies might be relevant prior experience. Studies have shown that the attitudes of people who have had direct prior experience with an attitude object were moderately related to subsequent attitude-relevant behaviors, whereas attitudes of people without direct experience had slight or no relationship (Fazio \& Zanna, 1978a).

Based on the above, prior experience of Internet-based communications tools such as E-mail, bulletin boards and online discussion forums should serve to strengthen user perceptions and enhance the consistency of the attitude-behavior relationship with respect to usage of these tools. Within the context of Internet communications technologies, subjects with prior experience would presumably be more likely to hold stronger perceptions as to the perceived usefulness of these technologies, based on their ability to generate more beliefs and past behaviors related to their experience. Yet, in a domain where weakly held attitudes based on limited experience are the norm, behavior and intention to behave might be influenced by a variety of factors that could make predicting outcomes difficult.

\section{Attitude Toward Use}

Attitude toward use has usually been conceived of, as in TAM and also the TORA, as a variable constructed on the basis of a subject's belief perceptions and evaluations of the consequences of engaging in some behavior. In their original conceptualization of attitude toward use within the TAM model, Davis, Bagozzi, and Warshaw (1989) found three distinct attitude components: attitudes toward success, failure and the process of learning to use or using a technology. Hubona and Geitz (1999) saw attitude as a moderator variable within TAM, influenced by the belief perception constructs and directly influencing intentions to use a technology.

Fazio (1986) contended that variables such as experience strengthen the attitude-behavior relationship because they are more accessible (i.e., more easily called up from the subject's memory upon contact with the attitude object). From Fazio's 
perspective, attitudes can be activated upon exposure to an attitude object, either called up from memory or automatically activated upon exposure. Attitudes can therefore have a greater or lesser degree of accessibility. Fazio held that the more accessible an attitude, the stronger it would be, and the stronger and more consistent the relationship between attitude and subsequent behavior.

\section{Rationale for the Study and Hypotheses}

Although significant evidence supporting TAM exists in the literature, limited research has been conducted on the effect of external variables and their influence on the perceived usefulness and perceived ease of use belief constructs. Further, researchers such as Robertson and Gatignon (1986) have argued that most research dealing with diffusion of technological innovations has typically utilized survey methodologies, as compared to experimental approaches designed to illuminate causal processes. Therefore, the rationale for this study is based on using a quasi-experimental approach to examine the effect of prior relevant experience on perceived usefulness and intent to use Internet-based communications tools to complete a communication task.

Based on Fazio's direct experience research, as well as the TAM user acceptance studies focusing on individual differences, it can be expected that subjects with greater prior experience of a technology will be more likely to use it than those who lack experience.

$\mathrm{H} 1$ : Behavioral intent to use Internet-based communications technology will be significantly higher among subjects with a high level of experience as compared to those with a low level of experience.

Further, those subjects with higher levels of prior experience should have a stronger sense of the perceived usefulness of the technology than those who lack a high level of experience.

$\mathrm{H}$ 2: Perceived usefulness will be significantly higher among subjects with a high level of experience of Internet-based communications technology compared to those with a low level of experience.

In addition to the predicted main effects, this study sought to make predictions as to the effect of model relationships on 
the basis of an experimental manipulation of the perceived ease of use variable. According to TAM, perceived ease of use and perceived usefulness are moderating variables that directly influence attitude toward use and behavioral intent to use. Within the context of this study, it seems likely that prior experience should directly affect perceived usefulness, but that manipulations of the subject's perception of the ease of use of a technology might influence behavioral intention. Due to the attitudes and perceptions formed on the basis of their prior experience, subjects with a high level of experience might be less susceptible to this influence than those who lack any relevant prior experience. Subjects with a high level of prior experience exposed to a stimulus message framing use of Internet communication tools as easy/beneficial to use should have a more positive behavioral intent than either subjects with a low level of prior experience and those exposed to a message framing Internet communications tools as difficult to use.

H3a: Behavioral intent will be highest for those subjects with high levels of prior experience who are in the high perceived ease of use condition;

H3b: Behavioral intent will be lowest for those subjects with low levels of prior experience who are in the low perceived ease of use condition.

Finally, the effect of prior experience on perceived usefulness should serve to make a significant contribution to the prediction of intent to use Internet communications tools for all subjects.

H4: Perceived usefulness and prior experience will prove to be the most significant predictor variables of behavioral intent for subjects with and without experience of the target adoption behavior.

\section{Methods}

\section{Research Design}

Subjects were drawn from a random sample of college students $(n=120)$ enrolled in an agricultural writing class. The research design was a $2 \times 2 \times 2$ factorial consisting of two levels (high and low) of experience, perceived usefulness and the perceived-ease-of-use message stimulus. To conduct the study, a questionnaire instrument was developed which was 
comprised of five-point bipolar semantic differential scale items. The prior experience variable was measured on the basis of a four-item index designed to measure subjects' experience with Internet communications tools, specifically, Email and on-line discussion forums. Perceived usefulness was measured on the basis of a 12-item index derived from the orginal TAM model. Perceived ease of use was manipulated on the basis of exposure to a message designed to frame usage of Internet communication tools as either easy to use and beneficial to the user, or as difficult to use and not beneficial. Attitude was measured by a ten-item index incorporating bipolar anchors focusing on attitude toward usage of Internet communications tools.

The dependent variables measured in the study, which included the 12-item perceived usefulness index, the ten-item attitude toward use index, and the five-item behavioral intent index, were derived from Hubana and Geitz's (1999) TAM scale. Relevant items were reverse coded so that in subsequent analysis, all items were scored to range from $1=$ least likely/ least favorable to $5=$ most likely/most favorable.

A panel of judges reviewed the questionnaire instrument and the perceived ease of use message stimuli for reliability and validity. In addition, a manipulation check was conducted to insure the validity of the perceived ease of use experimental manipulation with the sample population.

\section{Procedure}

At the beginning of the experiment, subjects were randomly assigned to one of the two perceived ease-of-use conditions, which were incorporated into the color-coded copy of the questionnaire booklet each subject received. After filling out the scale items that measured level of prior experience, subjects were instructed to read a one-paragraph message statement and then complete the rest of the questionnaire.

Subjects in the high perceived ease-of-use condition were exposed to the following message:

Sending a document electronically, either through an Email message that contains an E-mail attachment or by posting to an on-line bulletin board forum, is one way of making sure that your communication gets there right away - and you can save a copy for yourself to prove 
you sent it. It's efficient, because such messages don't require that you print out a hard copy version, so you save on paper, and convenient because you can do it right on your computer.

Subjects in the low perceived ease-of-use condition were exposed to the message that follows:

Sending a document electronically, either through an Email message that contains an E-mail attachment or by posting to an online bulletin board forum, may be a problematic form of communication, since your communication could get lost or deleted without your being aware of it. It requires that you have access to a computer that's fast enough to access the Internet and run the special software that is needed, and it may not be very convenient, since you need to learn how to use the software in order to send your document.

In the items which followed, subjects were asked to indicate their perceptions as to the perceived usefulness, as well as their attitude and behavioral intent toward using two specific forms of Internet communication, sending an E-mail attachment and posting a message to an on-line discussion forum, to complete a communication task involving communicating details about an assignment required in the class they were taking. Finally, at the end of the questionnaire, subjects were asked to re-read the perceived ease-of-use message statement, and then to answer a series of four items designed to serve as a manipulation check on respondents' interpretation of the message statement contents as a statement indicative of either a high or low perception of the ease of use of the specified Internet communication tools.

\section{Results}

Exploratory factor analysis was conducted on all of the variable indices in the study, resulting in a one-factor solution for all of the indices used in the analysis. For all hypotheses, descriptive statistics were obtained and mean splits were used to recode the independent variables into high and low levels. Reliability analyses for all of the indices used in the study were subsequently run using Chronbach's alpha statistic. The resulting standardized item alpha for the experience scale was .62. Standardized item alpha for perceived usefulness was .90; for attitude .89; and for behavioral intention .72. 


\section{Hypotheses Tests}

Hypothesis 1, which predicted that behavioral intent would be higher for subjects with a high level of prior experience than for subjects with a low level of prior experience, was supported. Multivariate analysis using ANOVA was conducted, results of which indicated a main effect for prior experience, $F(1,118)=5.61, p<.02$. Comparison of means as displayed in Table 1 revealed that subjects with a high level of experience had a stronger behavioral intent than did subjects with a low level of experience.

Table 1 Comparison of Means for Effect of Experience on Behavioral Intent

\begin{tabular}{|llll|}
\hline & $\mathrm{n}$ & $\mathrm{M}$ & $\mathrm{SD}$ \\
High level of experience & 66 & 3.42 & .67 \\
Low level of experience & 53 & 2.90 & .80 \\
\hline
\end{tabular}

Hypothesis 2, which predicted that perceived usefulness would be higher for subjects with a high level of experience of Internet communications tools than for those subjects with low levels, was supported. ANOVA results revealed a main effect for experience, $F(1,119)=4.54, p<.03$, which indicated that subjects with higher levels of experience had a more favorable perception of the usefulness of Internet communications tools than did subjects with a lower level of experience of these technologies. Table 2 displays these results.

Table 2 Means for Effect of Experience on Perceived Usefulness

\begin{tabular}{|llll|}
\hline & $n$ & $M$ & SD \\
High level of experience & 67 & 3.44 & .75 \\
Low level of experience & 53 & 3.14 & .79 \\
\hline
\end{tabular}

For hypotheses $3 \mathrm{a}$ and $3 \mathrm{~b}$, which predicted that behavioral intent would be highest for subjects with high levels of experi- 
ence who were exposed to the high perceived ease-of-use message, and lowest for subjects with low levels of experience who were exposed to the low perceived ease-of-use message, was partially supported. Although no three-way interaction was found, a two-way interaction between experience and perceived usefulness was found, $F(1,118)=1.89, p<.05$. Comparison of means revealed that behavioral intent was highest for subjects who were high in level of experience and perceived usefulness and lowest for subjects who were low in level of experience and perceived usefulness (Table $\mathbf{3}$ ).

Table 3 Means for Effect of Experience and Perceived Usefulness on Behavioral Intent

\begin{tabular}{|c|c|c|c|c|}
\hline \multirow{3}{*}{$\begin{array}{l}\text { High Level of Experience } \\
\text { Low Level of Experience }\end{array}$} & \multicolumn{2}{|c|}{$\begin{array}{l}\text { High Perceived } \\
\text { Usefulness }\end{array}$} & \multicolumn{2}{|c|}{$\begin{array}{l}\text { Low Perceived } \\
\text { Usefulness }\end{array}$} \\
\hline & 3.98 & $\mathrm{SD}=75$ & 3.17 & $S D=63$ \\
\hline & 3.79 & $S D=.73$ & 2.08 & $\mathrm{SD}=1.33$ \\
\hline
\end{tabular}

Hypothesis 4, which predicted that perceived usefulness and experience would be the strongest predictor variables of behavioral intent to use Internet communications tools, was supported. To test this hypothesis, all TAM predictor variables were loaded into a linear regression model that utilized the behavioral intent index as the dependent variable. Linear regression analysis was performed, and the regression proved to be significant, $F(3,118)=17.08, p<.001$. Results indicated that, for all subjects, experience and perceived usefulness were the most significant predictors of behavioral intent to use Internet communications tools (Table 4).

Table 4 Prediction of Behavioral Intent to Use Internet Communications Tools

\begin{tabular}{|lcll|}
\hline Variables & $\mathrm{R}$ & Beta & $\mathrm{R}^{2}$ \\
\hline Attitude TowardUse & .07 & .077 & \\
Experience & .24 & $.407 * *$ & \\
Perceived Usefulness & .38 & $.247 * *$ & .555 \\
\hline$* * p<.01$ & & & \\
& & & \\
\hline
\end{tabular}




\section{Discussion and Conclusions}

This study provides support for the usefulness of the TAM model in terms of predicting adoption and usage of technological innovations such as Internet communications tools by agricultural audiences. In addition, the study supports the argument that external factors such as prior experience do play a role in acceptance of these technologies and ultimate usage behavior. It seems clear that individuals with relevant prior experience are the most likely to accept and use these technologies. As agriculture becomes more technologically focused on use of the Internet to transmit information, conduct transactions and communicate to diverse clientele, an implication of these findings may involve a need to more seriously consider the level of relevant prior experience of an audience when implementing new communications technology. This may be an issue with Extension audiences, in particular. Extensionists themselves may find themselves in a "train the trainer" situation with respect to using communications technologies that may be as new to them as to the clientele they serve.

The lack of any significant interactions between the perceived ease-of-use message stimulus and the other model variables seems to suggest that experience exerts a direct influence on an individual's perceptions of the usefulness of a technology to complete a specific task or achieve an objective, as opposed to impacting subjects' evaluations of the perceived ease or difficulty associated with a technology's use. This seems logical, since prior experience would seem to have a definite association with an individual's determination of the usefulness, or lack thereof, of adopting some technology. Further research in this area, looking more specifically at the paths of interaction and direction of influence of the relevant prior experience variable, appears warranted on the basis of this study. A study of these same model relationships with Extension educators and their clientele is another area for future research.

In addition to the above, one of the key findings of this study involves the implication that relevant prior experience interacts with perceived usefulness to serve as a highly significant predictor variable of behavioral intent toward usage, while the attitude variable seems to have little impact. The implications 
of this finding are important, since although most individuals know of and have pre-existing attitudes about the Internet in general, it is a still a relatively young and still evolving communication medium. The level of usage, and consequently, experience of Internet communication tools within an agricultural audience is likely to be relatively low compared to usage of the Internet itself as a purely information tool. Even in the classroom setting, many students' experience of these technologies is limited to browsing a Web page as part of a class assignment or to gain material for research.

Based on the results of this study, it would seem apparent that it is not only an audience's level of experience, but also the quality of that experience that will be a critical factor in determining usage behavior. From the institutional perspective, there are obvious incentives in developing communications that utilize technologically innovative techniques such as Internet communications tools. But, while early adopters may be intrinsically motivated to adopt a new technological innovation and ignore any minor disadvantages or risks, the larger populations of late adopters and early majorities may have quite different experiences, perceptions and motivations which drive their adoption behavior. To be successful, a technologically innovative communication tool may need not only to be perceived as effective, but also capable of being framed according to the benefits of its use and the positive prior experiences of at least some users who are also members of the potential audience.

Based on the results of this study, it seems likely that whether in the classroom, or in communicating to an eternal audience, it would be helpful to integrate opportunities to let audiences try out a new communications technology before implementing it. The undeniable efficiency and potential of Internet communication tools, in the classroom, in the field, in the county extension office and with the public in general, provides a compelling rationale for continued efforts aimed at growing the experience base and providing opportunities for our constituencies to access and use these tools to communicate about important agricultural issues. In the classroom setting especially, it seems even more critical that our students continue to be exposed to evolving communications technologies. The skills and experiences they develop in these areas will not only assist the technology transfer process, but also 
enable them to more readily perceive the benefits and efficiencies these tools can provide.

\section{References}

Agarwal, R., \& Prasad, J . (1997). The role of innovation characteristics and perceived voluntariness in the acceptance of information technologies. Decision Sciences J ournal, 28 (3), 557-582.

Agarwal, R., \& Prasad, J . (1999). Are individual differences germane to the acceptance of new information technologies? Decision Sciences J ournal, 30 (2), 361-391.

Chau, P. Y. K., (1996). An empirical assessment of a modified technology acceptance model. J ournal of MIS, 13 (2), 185-204.

Davis, F. D., (1989). Perceived usefulness, perceived ease of use and user acceptance of information technology. MIS Quarterly, 13 (3), 319-339.

Davis, F. D., Bagozzi, R. P., \& Warshaw, P. R. (1989). User acceptance of computer technology: A comparison of two theoretical models. Management Science, 35 (8), 982-1003.

Doll, W. J ., Hendrickson, A., \& Deng, X. (1998). Using Davis' perceived usefulness and ease-of-use instruments for decision making: A confirmatory and multigroup invariance analysis. Decision Sciences J ournal, 29 (4), 839-869.

Donaldson, J . L., \& Thompson, J . S. (1999). Interpersonal communication strengthens Web-based instruction. J ournal of Applied Communication, 83 (3), 22-32.

Fazio, R. H. (1986). How do attitudes guide behavior. In R. M. Sorrentino, \& E. T. Higgins (Eds.), Handbook of motivation and cognition. New York: NY: Guilford Press.

Fazio, R.H. (1995). Attitude accessibility and motivation as determinants of biased processing: A test of the MODE model. Personality and Social Psychology Bulletin, 21 (7), 704-710.

Fazio, R. H., \& Zanna, M. P. (1978a). Attitudinal qualities relating to the strength of the attitude-behavior relationship. J ournal of Experimental Social Psychology, 14, 398-408.

Fishbein, M., \& Ajzen, I. (1975). Belief, attitude, intention and behavior: An introduction to theory and research. Reading, MA: Addison-Wesley.

Hendrickson, A. R., \& Collins, M. R. (1996). An assessment of structure and causation of IS usage. The DATABASE for Advances in Information Systems, 27 (2), 61-67.

Hirschman, E. C. (1980). Innovativeness, novelty seeking and consumer creativity. J ournal of Consumer Research, 7, 283-295.

Hubona, G. S., \& Geitz, S., (1999). External variables beliefs, attitudes and information technology usage behavior. [On-line]. 
A vailable: http:// www.isy.vcu.edu/ ghubona/ Pub1.html. [1999, Oct. 15].

Martin, E., \& Rainey, L. (1993). Student achievement and attitude in a satellite-delivered high school science course. The American J ournal of Distance Education, 7 (1), 54-61.

Matrix Information and Directory Services. (1997). [On-line]. Available: http://www. mids.org.[1999, Oct. 15].

Means, B. (1993). Using technology to support education reform. Washington, D.C.: Office of Educational Research and Improvement.

Miller, G., \& Pilcher, C. (1999). Desired and assessed cognitive levels of instruction: Are college of agriculture courses taught on campus and at a distance comparable? Proceedings of the $26^{\text {th }}$ National Agricultural Education Research Conference, 343-351.

Nielson, J ., (1995). Multimedia and hypertext: the Internet and beyond. Boston, MA: AP Professional.

Robertson, T. S. \& Gatignon, H. (1986). Competitive effects on technology diffusion, J ournal of Marketing, 50, 3, (J uly), 1-12.

Suvedia, M., Campo, S., \& Lapinski, M. K. (1999). Trends in Michigan farmers' information-seeking behaviors and perspectives on the delivery of information. J ournal of A pplied Communication, 83 (3), 33-49.

Trede, L. D., \& Whitaker, S. (1998). Perceptions of lowa beginning farmers toward the delivery of education. J ournal of A pplied Communication, 82 (4), 22-33.

Venkatesh, V. (1999). Creation of favorable user perceptions: exploring the role of intrinsic motivation. [On-line]. Available: http://www.mbs.umd.edu/is/venkate/ myhomepage/misq99/ misq1.htm. [1999, Oct. 15]. 